\title{
Platelet indices in diabetics and influence of glycemic control - a hospital based study in North-East India
}

\author{
Bhattacharjee $\mathbf{P}^{1}$, Datta $\mathrm{A}^{2}$, Debbarma R.K. ${ }^{3}$, Das S.K. ${ }^{4}$ \\ ${ }^{1}$ Dr. Prasun Bhattacharjee, Registrar, Department of Medicine, ${ }^{2}$ Dr. Abhijit Datta, Associate Professor, Department of \\ Pathology, ${ }^{3}$ Dr. Rajesh Kishore Debbarma, Associate Professor, Department of Medicine, ${ }^{4}$ Dr. Swapan Kumar Das, \\ Assistant Professor, Department of Medicine, all authors are affiliated with Agartala Govt. Medical College \& GB Pant \\ Hospital, Agartala, Tripura, India
}

Address for correspondence: Dr. Abhijit Datta, Email: abhijitpath62@gmail.com

\begin{abstract}
Introduction: Platelets from patients with type 1 and type 2 diabetes exhibit enhanced platelet aggregation activity early in the disease course that may precede the development of cardiovascular diseases. Both atherosclerosis and thrombosis appear to contribute significantly to the increased cardiovascular risk of diabetic patients. Platelet indices include mean platelet volume (MPV), platelet distribution width (PDW), and platelet large cell ratio (P-LCR). This study was undertaken with the aim to find out the differences in platelet indices between diabetics and non-diabetics and also between patients with controlled and uncontrolled diabetes mellitus in a tertiary health care centre in North East India. Methods: This is a cross sectional study conducted in Agartala Government Medical College and GB Pant Hospital (AGMC \& GBP Hospital). 100 cases and 100 controls were selected from the Diabetes clinic of Medicine out patient department (OPD) and Medicine wards. Platelet indices and $\mathrm{HbA}_{1} \mathrm{C}$ levels of these cases and controls were measured. Platelet indices were measured by a 3-part differential hematology auto-analyzer and $\mathrm{HbA}_{1} \mathrm{C}$ by High Performance Liquid Chromatography (HPLC) method. Blood glucose levels were estimated by oxidase-peroxidase method. Results: Platelet indices were found to be significantly higher among diabetics compared to non-diabetics and also they were found higher among patients with poor glycemic control with $\mathrm{HbA}_{1} \mathrm{C}>7 \%$ in comparison to patients with good glycemic control with $\mathrm{HbA}_{1} \mathrm{C}<7 \%$ ( $\mathrm{P}$ value $<0.05$ ). Conclusions: Platelet indices are significantly increased in diabetics and the extent of increment is more in diabetics with poor glycemic control.
\end{abstract}

Keywords: Glycosylated haemoglobin, Mean platelet volume, Platelet distribution width, Platelet indices, platelet large cell ratio.

\section{Introduction}

Diabetes Mellitus refers to a group of common metabolic disorders that share the phenotype of hyperglycemia. It may be due to insulin insufficiency (type 1) or insulin resistance (type 2) or both [1]. Cardiovascular disease (CVD) is the leading cause of disability and premature mortality in patients with diabetes [2]. Diabetes increases the risk for coronary heart disease (CHD), stroke, and peripheral arterial disease (PAD) from twofold to fourfold [3, 4]. The increased risk is independent of and additive to other cardiovascular (CV) risk factors, such as hypertension,

Manuscript received: 04 $4^{\text {th }}$ December 2016

Reviewed: $10^{\text {th }}$ December 2016

Author Corrected: $19^{\text {th }}$ December 2016

Accepted for Publication: $31^{\text {st }}$ December 2016 albuminuria, obesity, cigarette smoking, and dyslipidemia, relative to non-diabetic patients with these comorbidities [5,6].

Platelets from patients with type 1 and type 2 diabetes exhibit enhanced platelet aggregation activity early in the disease course that may precede the development of CVD [7,8,9].

The majority of ischemic coronary and cerebrovascular events are precipitated by vessel occlusion caused by atherosclerotic plaque disruption, platelet aggregation, platelet adhesion, and result an intravascular thrombosis. Several systems that maintain the integrity and patency of the vasculature are impaired in diabetes, including platelet and endothelial function, coagulation, and fibrinolysis [10,11]. Thus, the balance in normal 
hemostasis is shifted to favor thrombosis, increasing CV risk

Platelet indices include mean platelet volume (MPV), platelet distribution width (PDW), and platelet large cell ratio (P-LCR). Among platelet indices mean platelet volume reflects changes in either platelet stimulation or the rate of platelet production, PDW is a measure of platelet heterogeneity, which in turn may be due to aging of platelets or heterogeneous demarcation of megakaryocytes and P-LCR is the measure of larger platelets [12].

MPV, a determinant of platelet function, is a newly emerging risk factor for atherothrombosis. Many studies have shown that increased MPV is one of the risk factors for myocardial infarction, cerebral ischaemia and transient ischaemic attacks [13-17]. Impaired fasting glucose (IFG) is probably a frequent glycaemic disorder in the general population, and is considered as a pre-diabetic state [18]. Altered platelet morphology and function have been reported in patients with DM, and MPV was found to be significantly higher in diabetic patients $[19,20]$. They are likely to be associated with the pathological processes and increased risk of vascular disease seen in these patients [21].

To our knowledge, in this north-eastern state of Tripura there have been no studies on platelet indices of diabetics till date. So, this study was undertaken with the aim to find out the differences in platelet indices between diabetics and non-diabetics and also between patients with controlled and uncontrolled diabetes mellitus, in a tertiary health care centre of the state.

\section{Materials and Methods}

This cross sectional study was conducted in the Department of Medicine in collaboration with Department of Pathology in AGMC \& GBP Hospital.

Subjects: Patients, both males and females, were selected randomly from the Diabetes clinic at AGMC \& GBP Hospital as well as inpatients from the Medicine wards, who fulfilled the American Diabetes Association (ADA) criteria for diabetes mellitus and were labeled as cases subjected to the inclusion and exclusion criteria mentioned below. Age and sex matched non-diabetic controls were selected from the Medicine OPD as well as from the Medicine wards, again subjected to the inclusion and exclusion criteria.
Based on the availability of cases of diabetes (satisfying inclusion and exclusion criteria) attending for the first time in Diabetes clinic or Medicine ward of AGMC (either already diagnosed or freshly diagnosed here), a total of 100 Cases and 100 matched Controls were taken up for this study.

\section{Inclusion criteria}

1. Subjects aged more than 12 years.

2. Subjects who gave consent to be included in the study.

\section{Exclusion criteria}

1. Anemic patients, $\mathrm{Hb}<13 \mathrm{gm} \%$ in male $\&<12 \mathrm{gm} \%$ in female.

2. Any diagnosed malignancy patients.

3. Patients on antiplatelet drugs.

4. Known case of quantitative and qualitative platelet disorder.

\section{Methodology}

The study was conducted in the Department of Medicine, Agaratala Govt Medical College \& GB Pant Hospital after obtaining approval from the Institutional Ethics Committee and informed consents from all subjects. Patients attending the Diabetes clinic daily from Monday to Saturday were selected randomly based on their blood sugar levels (fasting, postprandial or random) and/or $\mathrm{HbA}_{1} \mathrm{C}$ values along with presence of symptoms of diabetes namely polyphagia, polydipsia, lethargy, weight gain or loss. Blood glucose levels were estimated by oxidase-peroxidase method. $\mathrm{HbA}_{1} \mathrm{C}$ was estimated by HPLC method. Similarly cases were also selected from among those admitted in the medicine wards. The ADA criteria were applied for selection of cases.

All blood specimens were drawn with minimal stasis from the ante-cubital vein using a dry sterile disposable syringe and needle and the specimens were labeled with subject's age, sex and identification number. The fluoride samples (for blood sugar estimation) and EDTA samples (for $\mathrm{HbA}_{1} \mathrm{C}$ level) were kept at room temperature until processed within 4 hours of collection.

They were evaluated for presence of coexistent obesity, hypertension and/or dyslipidemia (as components of the metabolic syndrome). 
Body Mass Index (BMI) was calculated according to the formula as below:

$\mathrm{BMI}=$ Body weight $($ in $\mathrm{kg}) /$ Height $(\text { in metres })^{2}$

Weight and height measurements were taken without heavy outer garments and shoes. The Asia-Pacific guidelines were used and obesity was defined as a BMI $\geq 25$.

Hypertension was defined as current use of antihypertensive drugs or systolic blood pressure > 140 $\mathrm{mmHg}$ and/or diastolic blood pressure $>90 \mathrm{mmHg}$. Lipid profile was estimated from a 12 hour fasting blood sample by the biochemical auto-analyzer XL-300 in the Department of Biochemistry, AGMC\& GBP Hospital.

Controls, matched for known confounding factors like age and sex were selected from Medicine OPD and also from the Medicine wards during this period.

Both Cases and Controls thus selected underwent measurement of their platelet indices viz. Mean platelet Volume (MPV), Platelet Distribution Width (PDW) and
Platelet-Large Cell Ratio (P-LCR) by Sysmex-XP 100, a 3-part automated cell counter in the Department of Pathology, AGMC \& GBP Hospital.

The platelet indices were compared between diabetic subjects and matched controls to see if significant differences exist. Similar comparisons were made among diabetic subjects (cases) to see if strict glycemic control of diabetes had any bearing on their platelet indices. The cases were divided into 2 groups: $\mathrm{A}$ and $\mathrm{B}$ based on their $\mathrm{HbA}_{1} \mathrm{C}$ levels $<7 \%$ and $\geq 7 \%$ respectively for good and poor glycemic control and their platelet indices were compared.

Statistical analysis- Statistical analyses were performed using the Statistical Package for the Social Science (SPSS). The categorical variables were shown as numbers of cases with percentage, and the continuous variables were shown as mean \pm standard deviation (SD). For univariate analysis of differences between the two groups, continuous variables were assessed with the unpaired Student's 't' test, and categorical variables with the chi-square test. A P-value of $\leq 0.05$ was considered statistically significant.

\section{Results}

Over a period of one year from 01/01/2014 to 31/12/2014, data on patients those attended the Diabetes clinic and Medicine wards at AGMC and GBP Hospital were collected. The total sample size was 200 which included 100 cases of diabetes and 100 age and sex matched non- diabetic controls. The analyses of the collected data are presented below.

The mean age of the patients having diabetes mellitus was $57.3 \pm 14.18$ years (calculated by the one sample T- test). The controls were also meticulously chosen ( 1 control per case) after matching for age. Hence age distribution of the controls was exactly similar to the cases.

Age distribution of cases and controls are shown in table-1. Males were marginally more in number (51\%) as compared to females (49\%). Controls as matched for gender, showed a similar distribution pattern. First, we compared the platelet indices (MPV, PDW and P-LCR ) between the diabetic patients and non diabetic controls. We observed that the platelet indices of diabetics are greater than that of the non-diabetics.

The MPV of diabetics was $12.65 \pm 1.89 \mathrm{fl}$ whereas the non-diabetics had a MPV of $11.16 \pm 1.18 \mathrm{fl}$. Similarly, the PDW of the diabetics was calculated to be $17.98 \pm 3.43 \%$. The PDW of the non-diabetics was $14.55 \pm 2.29 \%$. The P-LCR in diabetics was $41.73 \pm 11.9 \%$, whereas in diabetics it was calculated to be $36.99 \pm 8.56 \%$. The p-value calculated by the unpaired T-test was found to be $<0.05$ in all the three parameters, which holds statistical significance. Comparison of platelet indices between diabetics and non diabetics can be seen in table-2.

Table-2: Age distribution of cases and controls

\begin{tabular}{|c|c|c|}
\hline Age Group & No. of Patients/Controls & Percentage \\
\hline $13-30$ & 3 & $3 \%$ \\
\hline $31-50$ & 29 & $29 \%$ \\
\hline $51-70$ & 48 & $48 \%$ \\
\hline$>70$ & 20 & $20 \%$ \\
\hline
\end{tabular}


Table-3: Comparison of platelet indices between diabetics and non-diabetics

\begin{tabular}{|l|l|l|l|}
\hline Platelet indices & $\begin{array}{l}\text { Diabetics } \\
(\text { mean } \pm \text { SD) }\end{array}$ & $\begin{array}{l}\text { Non-diabetics } \\
(\text { mean } \pm \text { SD })\end{array}$ & P value \\
\hline MPV (fl) & $12.65 \pm 1.89$ & $11.16 \pm 1.18$ & 0.03 \\
\hline$\underline{\text { PDW (\%) }}$ & $17.98 \pm 3.43$ & $14.55 \pm 2.29$ & $<0.001$ \\
\hline$\underline{\text { P-LCR (\%) }}$ & $41.73 \pm 11.9$ & $36.99 \pm 8.56$ & 0.04 \\
\hline
\end{tabular}

Table-3: Differences in measures of platelet indices between patients with good glycemic control (group-A) and patients with poor glycemic control (group-B)

\begin{tabular}{|l|l|l|l|}
\hline Platelet Indices & \begin{tabular}{l} 
Group A \\
\cline { 2 - 2 }
\end{tabular} & $\begin{array}{l}\text { Group B } \\
\text { (mean } \pm \text { SD) }\end{array}$ & P Value \\
\hline $\begin{array}{l}\text { Mean Platelet Volume } \\
(\text { MPV) (fl) }\end{array}$ & $11.97 \pm 1.15$ & $12.98 \pm 0.95$ & 0.02 \\
\hline $\begin{array}{l}\text { Platelet Distribution Width } \\
\text { (PDW) (\%) }\end{array}$ & $17.14 \pm 2.46$ & $21.66 \pm 2.45$ & 0.01 \\
\hline $\begin{array}{l}\text { Platelet - Large Cell Ratio } \\
\text { (P-LCR) } \\
(\%)\end{array}$ & $38.54 \pm 9.08$ & $52.36 \pm 6.49$ & $<.001$ \\
\hline
\end{tabular}

For analytical purposes, we divided diabetic patients into two (2) groups as below, based on their status of glycemic control :

$\underline{\text { Group A }} \rightarrow$ Good glycemic control with $\mathrm{HbA}_{1} \mathrm{C}$ levels $<7 \%: 34$ patients.

$\underline{\text { Group B }} \rightarrow$ Poor glycemic control with $\mathrm{HbA}_{1} \mathrm{C}$ levels $\geq 7 \%: 66$ patients.

The mean $\mathrm{HbA}_{1} \mathrm{C}$ level of the cases was $\mathbf{7 . 2 9} \pm \mathbf{1 . 1 8 \%}$ (calculated by one sample t-test).

Differences in measures of platelet indices between patients with good glycemic control and patients with poor glycemic control are shown in table-3. From the table, we conclude that the platelet indices increase in patients with a poor glycemic status. The mean platelet volume (MPV) of the patients with poorly controlled hyperglycemia (Group B) was found to be $12.98 \pm 0.95 \mathrm{fl}$; whereas in those diabetic patients with a good glycemic status (Group A), the MPV was $11.97 \pm 1.15 \mathrm{fl}$.The $\mathrm{p}$-value using unpaired t-test was 0.02 .

Similarly, the platelet distribution width (PDW) of the patients with a poor glycemic control was $21.66+2.45 \%$, whereas the other group with a good glycemic control had a PDW of $17.14 \pm 2.46$ and the p-value was calculated as 0.01 .

The platelet large cell ratio (P-LCR) was calculated to be $52.36 \pm 6.49 \%$ in the poorly controlled (hyperglycemia) set of patients and $38.54 \pm 9.08 \%$ in the patients with a good glycemic control with an extremely significant $p$-value of < 0.001 .

\section{Discussion}

In this study the age of cases ranged from 17 to 84 years. The mean age of this study population was $57.3 \pm 14.18$ years. There were $51(51 \%)$ males and $49(49 \%)$ females.

Yenigun et al. in their study on Mean Platelet Volume in diabetes mellitus patients had a study population of 48 cases with mean age of $59.35 \pm 9.04$ years [22]. In their study they had 15 males and 33 females. This was different from our study which showed an almost equal gender predilection, probably owing to the markedly reduced sample size in their study as also a much shorter study period of only 4 months necessitating quick random recruitment of cases. 
A study by Kodiatte et al. correlating the difference in mean platelet volume in diabetics compared to non -diabetic revealed a mean age of $55 \pm 11.32$ years, closely corroborating with our findings [23]. However, their study population of 255 subjects also showed gender difference, 166 being males and only 89 being females unlike our study.

\begin{tabular}{|l|l|l|l|}
\hline Study Series & Males in \% & Females in \% & Mean Age (years) \\
\hline Our study & 51 & 49 & $57.3 \pm 14.18$ \\
\hline Yenigun et al. [22] & 31.3 & 68.7 & \\
\hline Kodiatte et al [23] & 65 & 35 & $59.35 \pm 9.04$ \\
\hline
\end{tabular}

In this study we found relatively higher values of all the platelet indices in both the study and control group subjects in comparison to other studies. However, the indices were all significantly increased in diabetic patients compared to matched non-diabetic controls as found in those studies. In this study the mean value of Mean platelet volume was 12.65 $\pm 1.89 \mathrm{fL}$ in diabetics and $11.16 \pm 1.18 \mathrm{fL}$ in the control group with a p-value of 0.03 . Similarly the mean Platelet distribution width was $17.98 \pm 3.43 \%$ and $14.55 \pm 2.29 \%$ in diabetic and control group subjects respectively (p value 0.001). The Platelet large cell ratio was also significantly increased in diabetics being $41.73 \pm 11.9 \%$ as against $36.99 \pm$ $8.56 \%$ in controls ( $\mathrm{p}$ value 0.04 ). The most significant difference was observed between the mean Platelet distribution width values of the diabetics and non-diabetics ( $\mathrm{p}$ value $<0.001$ ).

Hekimsoy et al in their study found a similar result in comparing Mean platelet volume of diabetics with that of healthy controls $(10.62 \pm 1.71 \mathrm{fl}$ vs. $9.15 \pm 0.86 \mathrm{fl}$; P<0.001) [21]. In a study by S. Jindal et al similar observations were made for all the three platelet indices with Platelet distribution width showing the strongest positive association with the glycemic state, as in our study [24]. Conversely, Ainsegun et al found Mean platelet volume to be higher in non diabetics $(8.69 \pm 0.67 \mathrm{fl}$ in diabetics and $8.91 \pm 0.80 \mathrm{fl}$ in the non-diabetic controls) [25]. However, the p value was found to be statistically non-significant $(\mathrm{p}=0.593)$.

\begin{tabular}{|l|l|l|l|}
\hline \multirow{2}{*}{ Study Series } & Mean Platelet Volume (fL) & \multirow{2}{*}{ P value } \\
\cline { 2 - 4 } & Diabetics & Non diabetics & \\
\hline Our study & $12.65 \pm 1.89$ & $11.16 \pm 1.18$ & 0.03 \\
\hline Hekimsoy et al. [21] & $10.62 \pm 1.71$ & $9.15 \pm 0.86$ & \\
\hline Jindal et al [24] & - & - & 0.00 \\
\hline Ainsegun et al. [25] & $8.69 \pm 0.67$ & $8.91 \pm 0.80$ & $<0.05$ \\
\hline
\end{tabular}

In this study, the platelet indices were all significantly raised among diabetics with poor glycemic control $\left(\mathrm{HbA}_{1} \mathrm{C} \geq 7 \%\right)$ as compared to those with tight control $\left(\mathrm{HbA}_{1} \mathrm{C}<7 \%\right)$. Platelet large cell ratio rise was seen to be most strongly associated with degree of glycemic control.

Kodiatte et al also divided their diabetic subjects into two groups according to status of glycemic control like our study and estimated Mean platelet volume in the two groups. They too found a significant increase in Mean platelet volume in the poorly controlled group as opposed to the group with good glycemic control $(8.35 \pm 0.724 \mathrm{fl}$ versus $7.95 \pm 0.72 \mathrm{fl}$; $\mathrm{p}=0.003$ ) [23]. Papanas et al however did not find any significant correlation between the Mean platelet volume levels and degree of glycemic control [20].

\section{Conclusion}

From this study we can conclude that platelet indices are significantly increased in diabetic patients compared to non-diabetics and the extent of increment is more in diabetics with poor glycemic control. But for the conclusion to be applicable for the general population, a study with a far larger sample size in the community needs to be carried out.
Another limitation of the study is that, other confounding factors like hypertension, obesity etc. which also affect platelet indices have not been taken into consideration here.

Funding: Nil, Conflict of interest: None initiated, Permission from IRB: Yes

\section{References}


1. Longo, Fauci, Kasper, Hauser, Jameson, Loscalzo. Harrison,s Principles of internal medicine. 18th edition. New York: McGraw-Hill Professional;2015

2. Nathan DM. Long-term complications of diabetes mellitus. N Engl J Med. 1993 Jun 10;328(23):1676-85. DOI: 10.1056/NEJM199306103282306

3. Stamler J, Vaccaro O, Neaton JD, Wentworth D. Diabetes, other risk factors, and 12-yr cardiovascular mortality for men screened in the Multiple Risk Factor Intervention Trial. Diabetes Care. 1993 Feb; 16 (2):434-44.

4. Brand FN, Abbott RD, Kannel WB. Diabetes, intermittent claudication, and risk of cardiovascular events.Diabetes. 1989 April; 38(4):504-9.

5. Reaven GM: Banting Lecture 1988: Role of insulin resistance in human disease. Diabetes. 1988 Dec; 37 (12):1595-1607.

6. Pahor M, Psaty BM, Furberg CD. New evidence on the prevention of cardiovascular events in hypertensive patients with type 2 diabetes.J CardiovascPharmacol. 1998; 32 (2) (Suppl. 2):18-23.

7. Halushka PV, Rogers RC, Loadholt CB, Colwell JA. Increased platelet thromboxane synthesis in diabetes mellitus. J Lab Clin Med. 1981 Jan; 97 (1):87-96.

8. Sagel J, Colwell JA, Crook L, Laimins M. Increased platelet aggregation in early diabetes mellitus. Ann Intern Med.1975 June ;82 (6) :733-8.

9. Mandal S, Sarode R, Dash S, Dash RJ. Hyperaggregation of platelets detected by whole blood platelet aggregometry in newly diagnosed noninsulindependent diabetes mellitus. Am J Clin Pathol. 1993 Aug;100 (2):103-7.

10. Jokl R, Colwell JA: Arterial thrombosis and atherosclerosis in diabetes. Diabetes Metab Rev1997; 5:1-15.

11. Jokl R, Colwell JA. Clotting disorders in diabetes.In International Textbook of Diabetes Mellitus. 2nd ed. Alberti KGMM, Zimmet P, DeFronzo RA, Keen H, Eds. Chichester, U.K., Wiley, 1997, p. 1543-57.
12. Schneider DJ. Factors contributing to increased platelet reactivity in people in people with diabetes. Diabetes care. 2009 April ;32(4):525-7.

13. Tavil Y, Sen N, Yazici HU. Mean platelet volume in patients with metabolic syndrome and its relationship with coronary artery disease. Thromb Res 2007; 120:24550

14. Khandekar MM, Khurana AS, Deshmukh SD. Platelet volume indices in patients with coronary artery disease and acute myocardial infarction: an Indian scenario. J ClinPathol. 2006 Feb; 59 (2):146-9.

15. Kiliçli-Camur N, Demirtunç R, Konuralp C, Eskiser A, BaşaranY. Could mean platelet volume be a predictive marker for acute myocardial infarction? Med SciMonit. 2005; 11:CR387-92.

16. Nadar SK, Lip GY, Blann AD. Platelet morphology, soluble Pselectin and platelet P-selectin in acute ischaemic stroke.The West Birmingham Stroke Project.ThrombHaemost 2004; 92 (1):1342-8.

17. McCabe DJ, Harrison P, Sidhu PS, Brown MM, Machin SJ. Circulatingreticulated platelets in the early and late phases after ischaemicstrokeand transient ischaemic attack. Br J Haematol.2004; 126:861-9.

18. O’Malley T, Langhorne P, Elton RA, Stewart C. Platelet size in stroke patients. Stroke 1995; 26:995-9.

19. Bock G, Dalla Man C, Campioni M. Pathogenesis of pre-diabetes: mechanisms of fasting and postprandial hyperglycemia in people with impaired fasting glucose and/or impaired glucose tolerance. Diabetes2006; 55 (2):3536-49.

20. Papanas N, Symeonidis G, Maltezos E. Mean platelet volume in patients with type 2 diabetes mellitus. Platelets 2004; 15 (1):475-8.

21. Hekimsoy Z, Payzin B, Ornek T, Kandoğan G. Mean platelet volume in Type 2 diabetic patients. J Diabetes Complications 2004;18 (1):173-6.

22. Yenigün EC, Okyay GU, Pirpir A, Hondur A, Yildırım IS. Increased mean platelet volume in type 2 diabetes mellitus. Dicle Medical Journal. 2014; 41 (1): $17-22$ 
23. Kodiatte TA, Manikyam UK, Rao SB, Jagadish et al. Mean Platelet Volume in type 2 Diabetes Mellitus. J Lab Physicians 2012; vol 4:p5-9

24. Jindal S, Gupta S, Gupta R, Kakkar A, Singh HV, Gupta $\mathrm{K}$ et al. Platelet indices in diabetes mellitus: indicators of diabetic microvascular complications. Hematology. 2011 Mar;16(2):86-9.
25. Akinsegun A, Olusola DA, Sarah JO, Olajumoke O, Adewumi A, Majeed O, Anthonia O, Ebele U, Olaitan O, Olanrewaju A and Kingsley A. Mean platelet volume and platelet counts in type 2 Diabetes: Mellitus on treatment and non-diabetic mellitus controls in Lagos, Nigeria.The Pan African Medical Journal. 2014;18:42. doi:10.11604/pamj.2014.18.42.3651.

\section{How to cite this article?}

Bhattacharjee, Datta A, Debbarma R.K., Das S.K. Platelet indices in diabetics and influence of glycemic control - a hospital based study in North-East India. Int J Med Res Rev 2016;4(12):2186-2192.doi:10.17511 /ijmrr. 2016.i12.18. 